\title{
ESTUDO SÔBRE 115 TUMORES DO LOBO OCCIPITAL
}

\author{
W. 'T Ö N N Is*
}

Os tumores do lobo occipital não têm despertado o interêsse que merecem do ponto de vista diagnóstico. A literatura consigna poucas comunicações a respeito (quadros 1 e 2 ).

\begin{tabular}{|c|c|c|c|c|}
\hline$A u t o r$ & Ano & $\begin{array}{l}\mathrm{N}^{o} \text { total de } \\
\text { casos }\end{array}$ & $\begin{array}{l}\text { Tumores } \\
\text { occipitais }\end{array}$ & $\%$ \\
\hline Cairns $\quad \ldots \ldots \ldots \ldots \ldots$ & 1927 & 162 & 9 & - \\
\hline Dowman e Smith ....... & 1928 & 100 & 2 & $2,0 \%$ \\
\hline Fracier e Waggoner .... & 1929 & - & 40 & 一 \\
\hline Allen $\quad \ldots \ldots \ldots \ldots \ldots$ & 1930 & - & 40 & - \\
\hline Cushing $\quad \ldots \ldots \ldots \ldots \ldots$ & 1932 & 1.191 & 40 & $\mathbf{3 , 3} \%$ \\
\hline Horrax e Putnam ...... & 1932 & 1.881 & 40 & $2,1 \%$ \\
\hline Benda $\ldots \ldots \ldots$ & 1934-36 & - & 11 & - \\
\hline Bennet $\quad \ldots \ldots \ldots \ldots \ldots$ & 1946 & 371 & 11 & $2,9 \%$ \\
\hline $\begin{array}{c}\text { Parkinson, } \text { Craig e Ker- } \\
\text { nohan } \ldots \ldots \ldots \ldots \ldots\end{array}$ & 1950 & - & 50 & $2-3,0 \%$ \\
\hline Tönnis $\quad \ldots \ldots \ldots \ldots \ldots$ & 1952 & 4.156 & 115 & $4,4 \%$ \\
\hline
\end{tabular}

Quadro 1 - Frequiência dos tumores occipitais segundo vários autores.

\begin{tabular}{|c|c|c|c|c|}
\hline$A u t o r$ & Ano & No de casos & Glioma & Meningioma \\
\hline Fracier e Waggoner .... & 1929 & 40 & $.14 \%$ & $26 \%$ \\
\hline$\ldots \ldots \ldots \ldots \ldots \ldots$ & 1930 & 40 & $40 \%$ & $10 \%$ \\
\hline Horrax e Putnam ...... & 1932 & 40 & $50 \%$ & $35 \%$ \\
\hline $\begin{array}{c}\text { Parkinson, Craig e Ker- } \\
\text { nohan } \ldots \ldots \ldots \ldots \ldots \ldots\end{array}$ & 1950 & 50 & $48 \%$ & $38 \%$ \\
\hline Tönnis $\ldots \ldots \ldots$ & 1952 & 115 & $52 \%$ & $31 \%$ \\
\hline
\end{tabular}

Quadro 2 - Diagnóstico histológico de tumores occipitais (revisão bibliográfica).

Aula proferida no Serviço de Neurologia da Escola Paulista de Medicina (Serviço do Prof. Paulino W. Longo) em 10 maio 1953. Texto traduzido por O. Lange.

* Diretor da Clínica Neurocirúrgica da Universidade de Colonia (Alemanha). 
Nosso relatório se baseia sôbre 115 casos de afecções expansivas localizadas no lobo occipital (quadro 3). E' de notar que os glioblastomas e os meningiomas são os tumores mais freqüentes. Comparando a freqüência de sua localização no lobo occipital com a freqüência total dos tumores intracranianos ver-se-á que a percentagem da localização occipital é importante.

\begin{tabular}{|c|c|c|c|}
\hline Tipo de tumor & $N^{\circ}$ de casos & Freqüência & $\begin{array}{l}\text { Freqüência em relação ao } \\
\text { número total de tumores } \\
\qquad(3.000 \text { casos })\end{array}$ \\
\hline Espongioblastomas $\ldots \ldots$ & 1 & $1,0 \%$ & $6,8 \%$ \\
\hline Oligodendrogliomas $\quad \ldots$. & 12 & $11,5 \%$ & $6,8 \%$ \\
\hline Astrocitomas $\quad \ldots \ldots \ldots$ & 8 & $7,6 \%$ & $8,0 \%$ \\
\hline Glioblastomas $\quad \ldots \ldots \ldots$ & 30 & $28,6 \%$ & $14,6 \%$ \\
\hline Ependimomas $\quad \ldots \ldots \ldots$ & 4 & $3,8 \%$ & $5,1 \%$ \\
\hline Meningeomas & 33 & $31,5 \%$ & $17,9 \%$ \\
\hline Sarcomas $\quad \ldots \ldots \ldots \ldots$ & 5 & $4,7 \%$ & $1,3 \%$ \\
\hline Não classificados $\ldots \ldots$. & 3 & $2,8 \%$ & $4,0 \%$ \\
\hline Metástases $\quad \ldots \ldots \ldots \ldots$ & 9 & $8,5 \%$ & $4,0 \%$ \\
\hline & 105 & $100,0 \%$ & \\
\hline Abscessos & 10 & & \\
\hline & 115 & & \\
\hline
\end{tabular}

Quadro 3 - Distribuição quanto à natureza dos 115 casos de afecções expansivas com localização occipital.

E' sabido que os tumores do lobo occipital são difíceis de diagnosticar. De 23 casos de meningiomas occipitais, 13 estavam com diagnóstico errado ao serem internados em nosso Serviço. Entre nossos 115 casos, apenas em 15 conseguimos um diagnóstico topográfico exato, baseado em sintomas clínicos e radiológicos. Considerando as anamneses, verifica-se que os sintomas de hipertensão intracraniana são mais freqüentes que os sintomas focais. 0 quadro 4 mostra que 3 casos sòmente não apresentavam sinais de hipertensão intracraniana, ao passo que 28 casos apresentavam hipertensão discreta e 84 outros apresentavam hipertensão elevada. Este último grupo encerra todos os casos de glioblastomas e de abscessos. 


\begin{tabular}{|c|c|c|c|}
\hline \multirow{2}{*}{ Tipo de tumor } & \multicolumn{3}{|c|}{ Hipertensão intracraniana } \\
\hline & Intensa & Nítida & Pouco nítida \\
\hline Espongioblastoma $\quad \ldots \ldots \ldots \ldots \ldots$ & 1 & - & - \\
\hline Oligondendrogliomas $\quad \ldots \ldots \ldots$ & 7 & 5 & - \\
\hline Astrocitomas $\quad \ldots \ldots \ldots \ldots \ldots$ & 7 & 1 & $一$ \\
\hline Glioblastomas $\quad \ldots \ldots \ldots \ldots \ldots$ & 30 & $\leftarrow$ & - \\
\hline Ependimomas $\quad \ldots \ldots \ldots \ldots \ldots$ & 4 & - & - \\
\hline \multicolumn{4}{|l|}{ Meningeomas: } \\
\hline convexidade $\quad \ldots \ldots \ldots \ldots$ & 5 & - & - \\
\hline seios venosos $\ldots \ldots \ldots \ldots \ldots$ & 4 & 7 & 2 \\
\hline tentoriais $\quad \ldots$ & 2 & 11 & 1 \\
\hline ventricular $\quad \ldots \ldots \ldots \ldots \ldots$ & - & 1 & - \\
\hline Sarcomas $\quad \ldots \ldots \ldots \ldots \ldots \ldots$ & 5 & $\cdots$ & - \\
\hline Não classificados $\ldots \ldots \ldots \ldots \ldots$ & $\mathbf{3}$ & $\cdots$ & 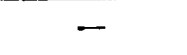 \\
\hline Metástases $\quad \ldots \ldots \ldots \ldots \ldots \ldots$ & 6 & 3 & - \\
\hline \multirow[t]{2}{*}{ Abscessos $\quad \ldots \ldots \ldots \ldots \ldots \ldots \ldots$} & 10 & - & - \\
\hline & 84 & 28 & $\mathbf{3}$ \\
\hline
\end{tabular}

Quadro 4 - Grau de hipertensão intracraniana nos 115 casos de afeç̃ões expansivas localizadas no lobo occipital.

Dos sintomas focais, o mais freqüente é a hemianopsia homônima. Freqüentemente os doentes chegam ao neurocirurgião tão tardiamente que já não é mais possível um exame pormenorizado do campo visual; isto se passou em $27 \%$ dos nossos casos. Em $14 \%$ dos casos foi verificado um estreitamento concêntrico do campo visual. E' preciso acrescentar que $11 \%$ dos doentes não apresentavam déficit visual algum. Isto dá um total de $52 \%$, isto é, aproximadamente a metade do total de casos, que não apresentavam sintomatologia focal occipital.

Ao contrário, os sintomas do lobo temporal vizinho se fazem notar com freqüência, sendo relativamente precoces. Em 55\% dos casos havia sinais dependentes de lesão do feixe piramidal. 
Assim, é possível que, pela falta de sintomas focais occipitais, o diagnóstico topográfico não seja acertado. Os resultados dos exames radiológicos também podem ser enganosos: em $45 \%$ dos casos encontramos alterações da sela turca e em $20 \%$, uma dilatação muito nítida da sela turca, causas freqüentes de êrro, conduzindo ao diagnóstico de tumor selar ou para-selar. Em nosso material, 6 casos foram tratados pela radioterapia como adenomas hipofisários e 2 foram operados erradamente.

E' a angiografia que merece interêsse especial. Segundo dados da literatura, é o empurramento e deslocamento da parte posterior dos vasos do grupo silviano que caracteriza os tumores do lobo occipital. Em 33 de nossos casos, nos quais foi feito êste exame, 15 apresentaram tal deslocamento dos vasos silvianos. Entretanto, nos casos restantes, as artérias posteriores e anteriores também sofriam deslocamentos; para explicar êste fato é preciso lembrar que ęm $2 / 3$ dos nossos casos de glioblastomas, o tumor se localizava no polo occipital.

Nos ventriculogramas nota-se, freqüentemente, que as deformações dos lobos frontais são mais acentuadas que as das partes occipitais, fato que conduz a erros diagnósticos. As alterações no eletrencefalograma em geral são observadas no mesmo lado em que localiza o tumor, mas elas freqüentemente aparecem também nos lobos parietal e temporal.

Em 100 de nossos casos, o tumor pôde ser extirpado. A mortalidade pós-operatória chegou a $18 \%$ do total, repartindo-se, em várias épocas, entre $22 \%$ e $14,5 \%$.

\begin{tabular}{|c|c|c|}
\hline$A \quad n \circ s$ & $\begin{array}{c}\text { Total de pacientes } \\
\text { operados }\end{array}$ & Mortalidade operatória \\
\hline $1932-1943$ & 45 & $10(22,2 \%)$ \\
\hline 1946-1952 & 55 & $8(14,5 \%)$ \\
\hline $1932-1952$ & 100 & $18(18,0 \%)$ \\
\hline
\end{tabular}

Quadro 5 - Mortalidade operatória nos tumores occipitais.

Conseguimos fazer o seguimento em 55 pacientes, observados até 16 anos após a intervenção: $47 \%$ dos casos morreram em conseqüência de recidivas; 6 pacientes ainda vivem, 12 anos após a intervenção. Dois terços dos pacientes operados retornaram ao trabalho ativo; a incapacidade para o trabalho foi devida, em primeiro lugar, pelos distúrbios da acuidade visual. 


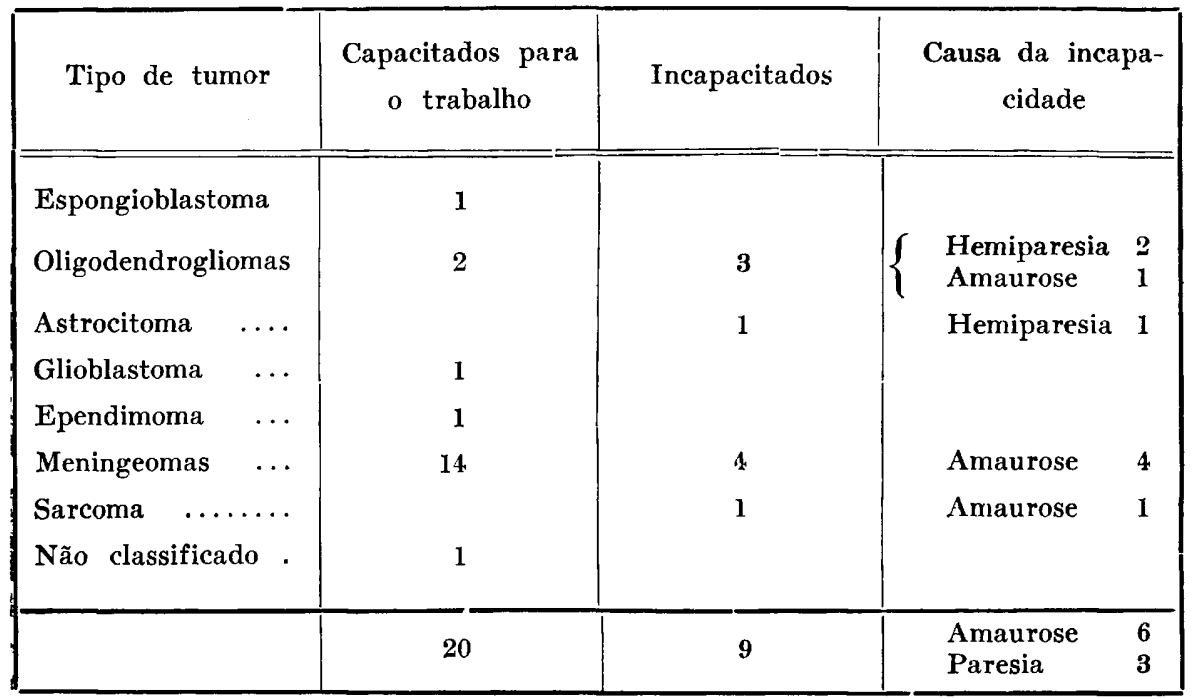

Quadro 6 - Resultados observados algum tempo após a operação.

Comparados com o de tumores localizados em outras partes do cérebro, o prognóstico dos tumores do lobo occipital nos parece relativamente favorável. Resultados melhores poderão ser esperados quando o diagnóstico fôr precoce.

Clinica Neurocinúrgica - Universidade de Colonia, Alemanha. 